\title{
ENGLISH LANGUAGE TEACHING IN INDONESIA: A CONTINUOUS CHALLENGE IN EDUCATION AND CULTURAL DIVERSITY
}

\author{
M. Marcellino \\ Universitas Katolik Atma Jaya, Jakarta
}

\begin{abstract}
The linguistic situations and conditions in Indonesia are quite complex by their own natures as more than seven hundred vernaculars with their various dialects from a great number of ethnic groups have been used as media of communication in the country. Accordingly, the success of English teaching in Indonesia cannot be freed from the students' cultural backgrounds, values, customs, and beliefs as well as the political standpoint of the government regarding this foreign language. English language teaching has then undergone more than four changes in its curriculum since the country's independence and brought no significant impact upon the learning outcomes. This study reveals the substantial unconstructive influence of the students' cultures and the non-conducive language environment affecting their language acquisition. Other aspects related to the teachers' performance and class preparations equally contribute to the ineffective classroom interactions. This study offers some practical suggestions to cope with those problems.
\end{abstract}

Key words: English, language, teaching, challenge, education, cultural, diversity

The Ministry of Education has recently introduced the competency-based language curriculum emphasizing the performance-based outcomes for each educational unit from primary to high schools in the forms of national stan- 
dards. This new approach requires an excessive demand for flexible and independent learning. However, the implementation of this approach has led to many problems owing to a number of cultural, professional, and practical factors.

From the cultural perspective, the basic features of this performance-based approach seem to be contradictory with the majority of Indonesian students' social and ethical values and beliefs as reflected by the dominant Javanese influence in classroom settings. Total obedience, unquestioning mind, and the belief that the old know all as well as that the teacher can do no wrong normally portray the learning atmosphere in many classes under study. Accordingly, the class hardly raised any question to the teacher, scarcely responded critically to the teacher's debatable and unsound statement or argument; instead they respectfully and compliantly did the teacher's instructions and believed that what was said was entirely correct (further readings on cultural aspects, see Dardjowidjojo, 2003).

Professional factors may cover the teacher's class preparations, mastery of the discussed topics, and teaching-learning strategies, among others. Practical factors refer to the number of students in class, class size, time allotment, lack of appropriate resources to support the implementation of the approach, to mention a few.

The competency-based teaching and learning model is not a grand new teaching-learning revolution in language teaching methodology. The expected learning outcomes as emphasized in this language instruction are similar to the traits as proposed in the Communicative Language Teaching (CLT) or in the Task-Based Language Instruction (TBLI). The ability to state one's preference or intention, for example, in Competency-based learning (CBL) is exactly the same as that in CLT and TBLI. The same thing is true for other traits as expected from all these curricula. In these approaches, learning outcomes are determined, produced, and evaluated explicitly as distinct measurement units within their own specific contexts and situations. In other words, these new paths lead directly to the teaching-learning current trends rather than changing the basic methodological paradigm of its kind.

The changes of English curricula since 1975 in our country have not yet brought any significant and substantial impact upon the ELT (English Language Teaching) class success. The main question is at what point teachers as practitioners or educators and theorists or language experts consider the class implementing a particular approach successful for teaching-learning interac- 
tions will never be exclusively dependent upon a particular teaching method (see Marcellino 2005, Setiono 2004a). Ling (1999) argues that competency is supposedly to be seen more broadly in CBL as it includes many demands rather than completing a single task. As a result, different teachers and raters may use different words to describe their students' competence. He further claims that assessment is always subjective and interpretative, and it may, thus, lead to biases in teachers or assessors making the judgments.

\section{WHY COMPETENCY-BASED LEARNING?}

The interest in performance-based learning stemming from specific knowledge, abilities, and skills as represented in the forms of competencies is accelerating throughout the world. There are at least three fundamental reasons why competency-based initiatives are vital. First, specific articulations of competencies inform and guide the basis of subsequent assessments of the course and program. Secondly, specific competencies assist teachers and students to possess a common understanding on the specific skills, knowledge, and abilities they have to acquire as a result of their learning experience. Thirdly, specific competencies provide directions for designing teaching materials and learning experience and assignments which can help learners gain practice in using and implementing the competencies they have acquired.

Docking (1994) asserts that a unit of competency can be realized in the forms of tasks, roles, functions, or a learning module. These will vary from contexts to contexts and may include specific knowledge, thinking processes, attitudes, and both perceptual and physical skills. The unit of progression is, then, the mastery of specific knowledge, the possession of particular skills and abilities in order to accomplish a given task within a specific context and situation (see Sullivan, 1995). In conjunction with this argument, Norton (1987) contends that competencies are, therefore, to be carefully selected, identified, and made possible to be demonstrated and assessed by the set criteria. Materials are then keyed to the competencies the class will achieve and have to be designed to support the acquisition of the specific knowledge and skills.

Learning from its basic features, CBL is then recommended as a key success for language learning. As CBL can be acclaimed to be based on functional and interactional perspectives, it seeks to teach language in conjunction with social contexts in which it is used. Accordingly, there is a shift in the imple- 
mentation of this approach, i.e. from what the learners know about the language to what they can do with it.

\section{THE STRENGTHS AND WEAKNESSES OF CBL - A THEORETICAL PERSPECTIVE}

Watson (1990) affirms that competency based approach is beneficial for learners as it helps attain a small number of specific knowledge and skills necessary for communication. Norton (1987) further argues that in CBL learners may build confidence as they can succeed in acquiring specific competencies. Another strength of CBL is that learning is self-paced so that each individual has his/her own development of the specified competencies.

Competency-based language programs rely on measurable assessment. Thus, any competence being evaluated has to be described unambiguously and subsequently tested. Under these circumstances, competencies are transparent (Voorhees, 2001).

As learning can be described and measured in a way they are apprehended by all parties, competencies permit the learners to return to one or more competencies that have not been acquired in the learning process. Competencies also provide learners with a clear map and tool needed to move expeditiously toward their goal (Voorhees, 2001).

Apart from its superior aspects, CBL has some potential limitations. One of its restrictions relates to the teacher's tendency to quickly slip back into the role of traditional teachers. Another problem deals with the possibility that the result of CBL is likely to be ineffective if no attention is given to the identification of essential skills necessarily needed for communication (Sullivan, 2005). As competency-based programs, according to Foyster (1990), have to be criterion-referenced with the criterion being the competence upon which the program is based, there has not been yet any standard norm used by schools to assess the specific competencies as in CBL.

In relation to this, Voorhees (2001) points out that efforts to define and assess competencies based on performance standards face a number of challenges. Some questions raised deals with what methodologies will be used to assess performance. Choices must be made among tests, portfolios, teacher ratings, and exemplars of performance. Ling (1999) sees competency more broadly as including many demands rather than completing a single task. Simi- 
larly, it is somehow difficult to ascertain "data ramifications" which ensure that competencies are both valid and reliable with the ultimate objectives. Data ramification here refers to the efforts to describe competencies in a uniform manner so as to possess the same meaning in various contexts and for a variety of audiences.

In support of the said argument, the issue of what core skills all high school graduates ought to possess then becomes problematic, given the diversity of students' prerequisite knowledge of the target language and the teachers' qualification and knowledge of CBL. In designing a competency-based learning environment, the challenge is to facilitate learning while providing authentic tasks (Nadolski et al, 2001). In this case, teachers' personal credentials are subject to question. Dardjowidjojo (2003) affirms that many teachers of English graduating from FKIP or IKIP (Teachers Training Institutes) have not yet even reached the maturity level in the use of English.

As CBL provides flexible and independent learning, a learner's progress varies from individual to individual at his / her own pace. Consequently, differences in traits and the characteristics help explain why learners have different learning experience, thus have to be treated individually as they may acquire different levels and kinds of language exposure and skills as well as knowledge and abilities in the use of the target language. Competencies are, then, the result of integrative learning experiences in which skills, abilities, and knowledge interact to form learning bundles that have prevalence in relation to tasks for which they are assembled (Voorhees, 2001). This study atmosphere may then unconstructively affect the class interactions in that the smart students may dominantly lead class discussions.

Another weakness of CBL concerns the requirement of different competencies for different topics of discussions as competencies within different contexts call for different bundles of skills and knowledge. Thus, the challenge is to determine which competencies can be bundled together to provide different types of learners with the optimal combination of skills and knowledge needed to perform an assigned and specific task. As learners have different levels of skills, knowledge, and abilities in the use of language, this makes it difficult for any teacher to maximize the effectiveness of class interactions. In both contexts, an ability to effectively coordinate the roles, timing, and contributions of all parties involved in class discussions becomes critical. When skill bundles are labeled identically, there is often difficulty in achieving a common under- 
standing of what a given competency is and what it means to assess it (see Voorhees, 2001).

Tollefson (1986) argues that CBL does not have any valid procedure to develop competency for most programs. Many of the areas for which competencies are needed in a community are impossible to operationalize. Others claim that dividing activities into sets of competencies is simplistic in that the sum of the parts may not be the same as the complexity of the whole. CBL is accordingly seen as prescriptivist in that it prepares the learners to master sets of language performances rather than on the development of thinking processes and skills.

\section{PROBLEMS OF CBL IMPLEMENTATION IN INDONESIAN CON- TEXTS}

As briefly discussed before, teachers of English in Indonesia encounter a number of problems when implementing this CBL model in class. A survey of six classes at five Senior High Schools implementing this approach and involving 258 students constitute the corpus of this research project. From class observations, it has been found out that a great number of English textbooks do not present grammatical aspects comprehensively as part of systematic presentations of the materials. As a result, teachers do not discuss grammaticality, an essential aspect of communicative competence (see Berns 1990, Johnson 1982, Littlewood 1981, Widdowson 1978, Wilkins 1972, 1981).

CBL puts an emphasis on learning outcomes; therefore, learners are granted the privilege to be self-directed and independent individuals. With this focus, a teacher's role has to be shifted from an authoritative agent to a facilitator, and this drastic change was rarely found in classes under investigation. In connection with this finding, Kirkpatrick $(1995,1996)$ states this paradigm shift, to a greater or lesser degree, may not be made possible as for many Asian societies "knowledge is traditionally seen as something to be transmitted down through generations," and that "the knowledge is passed down from teachers to students."

The language environment as well as the students' motivation to learn the language still become the core problems CBL teachers have to confront. As English is mandatory at high schools and that the students are obliged to learn 
it, their motivation to study is subject to question given the fact that they live in an environment in which knowledge of English is not compulsory.

The cultural barriers from the most dominant ethnic groups are still prevalent in class in that the majority of the class remains passive, do not critically respond to the teacher's argument or explanation, and compliantly abide by their teacher's instructions. As a result, the class interactions are mostly apathetic and only very few students are actively engaged in class and / or group discussions due to their high level of language proficiency.

The CBL model presumes that the teachers are knowledgeable of the basic tenets and procedures of this approach. The survey indicates that teachers are not well-equipped with the proper knowledge of CBL which requires dynamic learning to enhance skills, knowledge, and abilities in the use of language in various contexts and situations. The study reveals that some teachers conduct an English class with such model in a laboratory, and this violates the CBL principle which integrates collaborative learning in its application. In the laboratory, students cannot actively interact with one another in class discussions so as to make it impossible for dynamic learning.

As CBL entails dynamic class interactions, a common class size of more than forty students is then to be broken down into small classes if CBL has to be effective. It consequently leads to a great number of new classes and calls for a large number of new teachers, a phenomenon being impossibly realized as it will be too costly for both private and state schools.

With regard to teachers' professionalism, this study finds out that teachers frequently use Indonesian to discuss the topic and, to a great extent, to explain grammatical aspects of the target language (TL) due to their poor mastery of English. The following samples illustrate their poor mastery of English:

Teacher: $Y a$ kemarin

Student: [mumbling]

Teacher: $Y a$... Simple Past Tense. When you used Simple Past Tense?

Student: [laughing]

Teacher: Form-nya gimana?

Student: [keep silent]

Teacher: Form-nya kan Subject + verb, ... verb-nya apa?

Student: Verb 2 !!!!

Teacher: Ya, Verb 2, untuk kejadian kemarin

Interviewer: How long have you been implementing this approach? 
Teacher: $\quad \mathrm{Hmm} \ldots$ it depend on the teachers, Okay .... But for me ... uuh ... May be ... Uuh ... I will ... using this .... uuh .... System as possible as I can is .... My concern ... uuh but for the others teachers...... I don't know.

Interviewer: What does competency means to you when talking about CBL?

Teacher: $\quad U u h m$... from this ... competence ... uuhm .... Competency is means.... We can do something, Okay? For example ... a student can speak in English all of the sentence in English so they get the competency.

From the conversation above, it is apparent that the teacher's language proficiency is very poor. Every sentence he made contains grammatical errors. Quite often the teacher is stumbling in expressing his ideas. From that of CBL.

Several teachers tend to quickly slip back into the role of traditional teachers that teach English using the Audio Lingual Method (ALM), an approach that has a set of different principles and beliefs from that of CBL. Accordingly, teachers use a lockstep technique in their teaching, spending almost the whole class time on drilling, substitutions, and language reinforcement. In this context, teachers played the role of A and the students of B in class. The following examples illustrate this argument:

A: Guys, say, she is going to happy, John.

B: John is going to happy.

A: Bill

B: Bill is going to happy

A: Going to home, they

B: They are going to home.

A: Good.

When a close task is given to class in which the students have guided and clear instructions and clues, they can perform very well. The teachers could assign the groups to make a guided dialogue, for example a conversation about health conditions illustrating people in a series of pictures.

Teacher: How is Shinta? (showing a picture of a sick woman holding her stomach)

Class: She is sick. OR Shinta has a stomachache. 
Teacher: (showing the class a picture of a healthy old man) How is he?

Class: He is very well / fine.

However, students found it difficult when assigned to do open tasks in which the teachers gave topics of general interests and the students were to select and perform the chosen topic. Tasks given to class that students found hard to accomplish dealt with making a dialogue of their own on any of their favorite musicians, artists, singers, film actors, etc.

A monotonous teaching technique still depicts the teacher's performance, a common phenomenon in classroom practice. The questions raised do not encourage the students to a response of various language expressions. The following examples demonstrate this argument:

Teacher: How are you, Dennis?

Student: I am fine, thanks.

Teacher: Oh, great. What about you, Andry? (a student next to Dannis)

Student: I am fine, too.

Teacher: Great. What about you, Gina? (a student next to Andry)

$$
\text { Uhm ... How are you, Gina? }
$$

Students are normally passive in class and only respond to the teacher's questions when asked. There are at least three primary reasons accounting for this class situation. First, the students' previous trainings do not expose this sort of interactive learning model to them. Second, their cultural values and beliefs somehow do not encourage them to challenge neither their teachers nor their classmates as it may somewhat indicate that they are showing off. Third, the survey shows that their command of English is relatively very poor - lack of vocabulary and expressions as well as mastery of grammar - so as to make them speak Indonesian most of the time in class settings. The following examples exemplify their poor mastery of English:

Teacher: Your motto?

Student: Is there a good .... Apa ya? [What am I supposed to say?]

Teacher: Repeat. Repeat. Ulangi. Ulangi.

Student: My motto, cool always.

Teacher: So, ... pattern-nya? Dia atas, di atasnya. Above the first pattern.

Student: Ini the first pattern, $y a$ ? [Is this the first pattern?]

Teacher: No! The second. 
Student: Ininya. Did apa namanya, Miss? [Did ... what is the name (of it)?]

Teacher: So, subject + did not $+\mathrm{V} 1$

There for the negative, then for the question. Any question, class about Simple Past?

Another issue that class teachers are to address is concerned with the class management, a frequent and daily problem of handling the students with respect to turn taking and making the class lively. Teachers normally give a student a question one at a time, leaving the class disorganized as they are chatting or doing anything they wish in their own language. This completely minimizes the teaching-learning effectiveness and, thus, reduces the expected learning outcomes, the fundamental fecet in CBL.

The last barrier deals with the class size and time allocation, in which the class holds more than forty students with the time allotment of forty-five minutes for an English lesson. As a result, it is difficult for any English teacher to implement the CBL model into which collaborative learning is incorporated. In conjunction with the time frame, it is suggested that sixty to ninety minutes be suffice for one meeting so that teachers can have sufficient time to review the previous lesson, introduce the new topic, and discuss it in order to maximize the expected learning outcomes.

\section{CONCLUSIONS AND SUGGESTIONS}

From the research findings, it can be deduced that the implementation of CBL model at five schools under investigation failed. Many aspects and variables mentioned before absolutely bring about a very negative impact upon the learning outcomes. The linguistic and non-linguistic factors equally contribute to this class failure. Suggestions are to be made in order to assist English teachers to implement this approach. Closed tasks undoubtedly work very well in classroom practice as students have significant aids in the forms of clear guidance, clues, and directions when doing the tasks. As the majority of students are not ready for the assigned tasks, various samples of language use related to the discussed topics may be of valuable assistance. In this case, teachers may ask their students to pay careful attention to how language elements are constructed to express a variety of ideas relevant for the topics of discussions. Upgrading programs on CBL models have to be frequently exposed to 
teachers of English so as to be knowledgeable of the various teaching and testing techniques when implementing this approach. Tutorial or remedial programs for the students are to be made in order to help develop the students' language proficiency, an essential aspect for the class interactions in the CBL model.

\section{REFERENCES}

Berns, M. 1990. Context of Competence: Social and Cultural Considerations in Communicative Language Teaching. New York: Plenum Press.

Dardjowidjojo, S. 2003. Rampai Bahasa,Pendidikan, dan Budaya. Jakarta: Yayasan Obor Indonesia.

Docking, R. 1994. Competency-based Curricula - the Big Picture. Prospect 9/2: 8-17.

Foyster, J. 1990. Getting to Grips with Competency-based Training and Assessment. Leabrook: TAFE National Center for Research and Development.

Hamied, F.A. 1996. EFL Program Surveys in Indonesian Schools: Towards EFL Curriculum Implementation for Tomorrow. In Jacobs, G. M. 1997. Language Classroom for Tomorrow. Singapore: SEAMEO Regional Language Center.

Johnson, K. 1982. Communicative Syllabus Design and Methodology. Oxford: Pergamon Press

Kirkpatrick, A.A. 1995. Language, Culture, and Methodology. In Tickoo, M. L. Language and Culture in Multilingual Societies. Singapore: SEAMEO Anthology 36.

Kirskpatrick, A.A. 1996. The Changing Face of English Teaching: Principles and Practice. A paper presented at International Conference on Higher Education in the $21^{\text {st }}$ Century: Mission and Challenge in Developing Countries, Hanoi.

Ling, P. 1999. Assessing Competency. Final report to NCVER. Seminar/1999/Ling.htm 
Littlewood, W. 1981. Communicative Language Teaching: An Introduction. Cambridge: Cambridge University Press.

Marcellino, M. 2005. Competency-based Language Instruction in Speaking Classes: Its Theory and Implementation in Indonesian Contexts. A paper presented at the Third Annual International Conference on Education, Hawaii, January 4-7, 2005

Marcellino, M. 2006. Competency-based Language Teaching in English Classes: Revisited. A paper presented at the Sixth International Conference on Competency-Based English Teaching: Theory and Reality, Institut Teknologi Bandung, the British Council, and University of Leeds, Bandung, February 21-23, 2006.

Nadolski. R.J., Kirschner, P.A., Van Merrienboer, J.J.G., Hummel, H.G.K. 2001. A Model for Optimizing Step Size of Learning Task in Competency-based Multimedia Practicals. ETR\&D, 49/3.

Norton, R.E. 1987. Competency-based Education and Training: A Humanistic and Realistic Approach to Technical and Vocational Instruction. A paper presented at the Regional Workshop on Technical/Vocational Teacher Training in Chiba City, Japan.

Setiono. 2004a. Competency-based Learning: Dreams and Realities. The Jakarta Post, June 29, 2004.

Setiono, 2004b. Students Need Learning Autonomy. The Jakarta Post, March 06, 2004.

Sullivan, R. 1995. The competency-based Approach to Training. JHPIEGO Strategy Paper.

Tollefson, J. 1986. Functional Competencies in the U.S. Refugee Program: Theoretical and Practical Problems. TESOL Quarterly 20(4): 649-664.

Voorhees, R.A. 2001. Competency-based Learning Models: A Necessary Future. New Direction for Institutional Research. No. 110.

Watson, A. 1990. Competency-based Vocational Education and Self-Paced Learning, Monograph Series. Sydney: Technology University.

Widdowson, H.G. 1978. Teaching Language as Communication. Oxford: Oxford University Press. 
Wilkins, D.A. 1972. An investigation into the Linguistic and Situational Content of the Common Core in a Unit/Credit System. MS. Strasbourgh: Council of Europe.

Wilkins, D.A. 1981. Notional Syllabuses Revisited. Applied Linguistics, 2(1). 